\title{
Utilização de células-tronco autólogas de medula óssea na regeneração do nervo tibial de coelhos mediante técnica de tubulização com prótese de silicone
}

\author{
Applyng of autologous stem cells from bone marrow in the regeneration of tibial nerve \\ of rabbits using the tubulization technique with silicone tube
}

\author{
Lucas Marques Colomé ${ }^{I}$ Cristiano Gomes ${ }^{\text {II }}$ Nadia Crosignani ${ }^{\text {II }}$ Ana Helena Paz ${ }^{\text {III }}$ Ana Ayala Lugo \\ Karina Magano Guimarães ${ }^{\mathrm{V}}$ Liziane Pinho Foerstrow $^{\mathrm{V}}$ Jardel Pereira Tessari $^{\mathrm{V}}$ \\ Letícia Marques ColomévI Dominguita Lühers Graça ${ }^{\mathrm{VII}}$ Luise Meurer $^{\mathrm{VIII}}$ \\ Eduardo Pandolfi Passos ${ }^{\mathrm{VIII}}$ Ney Luis Pippi ${ }^{\mathrm{IX}}$ Emerson Antonio Contesini $^{\mathrm{X}}$ \\ Elizabeth Obino Cirne Lima ${ }^{\mathrm{XI}}$
}

RESUMO

Neste estudo é apresentado um modelo experimental de defeito agudo em nervo periférico para avaliação da regeneração nervosa mediante técnica de tubulização associada à inoculação de células-tronco autólogas de medula óssea. Foram utilizados 12 coelhos Nova Zelândia albinos, submetidos à secção bilateral $e$ ao afastamento de $5 \mathrm{~mm}$ do nervo tibial e posterior reparo mediante utilização de câmara de silicone. Internamente à prótese de tubulização do nervo tibial esquerdo em todos os animais, foram inoculadas células-tronco autólogas de medula óssea, coletadas a partir do úmero. Como grupo controle (nervo tibial direito), mediante aplicação da mesma técnica de reparo, solução de $\mathrm{NaCl}$ 0,9\% foi administrada internamente à prótese. Após 30 dias de observação, os animais foram eutanasiados $e$ foi realizada a avaliação histológica dos segmentos nervosos por meio das colorações de hematoxilina-eosina, luxol fast blue e azul de toluidina. Com os resultados, foi possível concluir que o transplante de células-tronco autólogas associado à técnica de tubulização apresenta vantagens no processo de regeneração nervosa periférica.

Palavras-chave: células-tronco, nervo tibial, tubulização, coelhos.

\section{ABSTRACT}

This study presents an experimental model of an acute deffect in a peripheral nerve to evaluate neural regeneration using a tubulization technique associated with the inoculation of autologous stem cells from bone marrow. A total of 12 New Zealand white rabbits underwent a bilateral dissection of the tibial nerve followed by repair with silicone tubulization. On the left tibial nerve of all animals, the tube was filled with autologous bone marrow-derived stem cells collected from the humerus. For control, using the same repair technique, the tubes were filled with a $\mathrm{NaCl}$ solution in the right tibial nerve. After 30 days of observation, the animals were euthanized and a histological evaluation of the collected nerve segments was performed by staining with hematoxylin-eosin, luxol fast blue, and toluidine blue. From the results it is possible to conclude that the transplanted autologous stem cells associated with the tubulization technique present an advantage in the peripheral nerve regeneration process.

Key words: stem cells, tibial nerve, tubulization, rabbits.

IPrograma de Pós-graduação em Medicina Veterinária, Universidade Federal de Santa Maria (UFSM), Santa Maria, RS, Brasil. Endereço para correspondência: Rua Vicente da Fontoura, 2895/401, 90640-003, Porto Alegre, RS, Brasil. E-mail: lucascolome@hotmail.com.

"Programa de Pós-graduação em Ciências Veterinárias, Universidade Federal do Rio Grande do Sul (UFRGS), Porto Alegre, RS, Brasil.

IIIPrograma de Pós-graduação em Medicina, Hospital de Clínicas de Porto Alegre (HCPA), UFRGS, Porto Alegre, RS, Brasil.

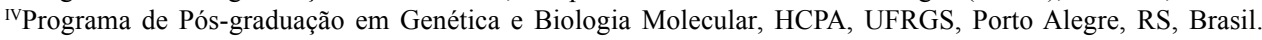

${ }^{\mathrm{v}}$ Curso de Medicina Veterinária, UFRGS, Porto Alegre, RS, Brasil.

${ }^{\mathrm{VI}}$ Departamento de Produção e Controle de Medicamentos, UFRGS, Porto Alegre, RS, Brasil.

VIIDepartamento de Patologia, UFSM, Santa Maria, RS, Brasil.

VIIIHospital de Clínicas de Porto Alegre, UFRGS, Porto Alegre, RS, Brasil.

${ }^{\mathrm{IX}}$ Departamento de Pequenos Animais, UFSM, Santa Maria, RS, Brasil.

${ }^{x}$ Departamento de Medicina Animal, UFRGS, Porto Alegre, RS, Brasil.

${ }^{\mathrm{x}}$ Departamento de Patologia Clínica Veterinária, UFRGS, Porto Alegre, RS, Brasil. 


\section{INTRODUÇÃO}

Lesões traumáticas e vasculares, inflamações e neoplasias podem produzir ruptura de algumas ou todas as fibras em um nervo periférico, resultando em disfunção sensitiva e/ou motora focal. A regeneração funcional após a reparação nervosa é um processo complexo, envolvendo fatores locais e sistêmicos. Neste particular, os mecanismos básicos de mielinização, crescimento e orientação das fibras regeneradas encontram-se ainda parcialmente nãodeterminados (DAZA et al., 1999).

No intuito de transpor estas dificuldades, pesquisas tem sido desenvolvidas a fim de conhecer o resultado da associação de técnicas consagradas com alternativas novas no âmbito da engenharia tecidual. A recente e promissora área da medicina regenerativa vem abrindo perspectivas inovadoras no tratamento de inúmeras doenças, utilizando terapias celulares, fatores de proliferação e diferenciação celular e biomateriais que permitem ao próprio organismo reparar tecidos e órgãos lesados. Como exemplo, pode-se citar a utilização de substâncias exógenas para promover um acréscimo na qualidade e na velocidade de regeneração (PINEDO, 2001; BARTH, 2006). Assim, muitos estudos vêm confirmando os benefícios da administração exógena de substâncias no microambiente gerado por meio da tubulização nervosa, entre as quais citam-se fatores neurotróficos, células em cultura e citocinas (TERENGHI, 1999; DA-SILVA et al., 2003; HEINE et al., 2004; CHEN et al., 2005; AQUINO et al., 2006).

Considerando isso, este trabalho teve por objetivo avaliar a capacidade de regeneração do nervo tibial de coelhos Nova Zelândia, mediante a associação da terapia celular por transplante de células-tronco mononucleares autólogas de medula óssea com a técnica de tubulização por meio de prótese de silicone.

\section{MATERIAL E MÉTODOS}

\section{Animais}

Foram utilizados 12 coelhos Nova Zelândia (Oryctolagus cuniculus) albinos, de ambos os sexos, com aproximadamente cinco meses de idade, pesando em média 2,1kg, provenientes da Escola Técnica Agrícola (ETA) de Viamão, Rio Grande do Sul (RS). Durante o período peri-operatório, os animais foram mantidos na Unidade de Experimentação Animal (UEA) do Hospital de Clínicas de Porto Alegre (HCPA). Os animais permaneceram em gaiolas individuais específicas, em ambiente com temperatura controlada, recebendo alimentação à base de ração comercial e água ad libitum.
Coleta e processamento de medula óssea

Foi realizada a extração da medula óssea bilateralmente a partir do tubérculo maior do úmero, utilizando-se agulha de Osgood $(25 \times 10)$ acoplada à seringa de $10 \mathrm{ml}$ heparinizada. Para realização desse procedimento, aplicou-se cetamina $\left(40 \mathrm{mg} \mathrm{kg}^{-1}\right)$, midazolan $\left(2 \mathrm{mg} \mathrm{kg}^{-1}\right)$ e citrato de fentanila $\left(8 \mu \mathrm{g} \mathrm{kg}^{-1}\right)$, todos por via intramuscular e isofluorano via máscara facial para manutenção do plano anestésico. As frações de medula óssea foram encaminhadas sob refrigeração ao Laboratório de Embriologia e Diferenciação Celular do HCPA. O aspirado celular foi processado e submetido à centrifugação por gradiente de FicollPlaque (Amersham Bioscience) a fim de separar a fração celular mononuclear do restante dos constituintes da medula óssea. O protocolo utilizado nesta etapa foi o mesmo desenvolvido por BOYUM (1968), e posteriormente modificado por NARDI \& ALFONSO (2006). As células mononucleares da medula foram separadas, analisadas quanto à viabilidade por coloração com azul de trypan e quantificadas em câmara de Neubauer.

Modelo experimental e transplante das células-tronco autólogas de medula óssea

Após o período de processamento da medula óssea, os animais foram novamente anestesiados utilizando-se cetamina $\left(40 \mathrm{mg} \mathrm{kg}^{-1}\right)$, midazolan $\left(2 \mathrm{mg} \mathrm{kg}^{-1}\right)$ e meperidina $\left(5 \mathrm{mg} \mathrm{kg}^{-1}\right)$ por via intramuscular e isofluorano via tubo endotraqueal em circuito semifechado. Solução de $\mathrm{NaCl} 0,9 \%$ foi administrada $\left(5 \mathrm{ml} \mathrm{kg}^{-1} \mathrm{~h}^{-1}\right)$ via cateter na veia marginal auricular. Todos os animais receberam ampicilina sódica $\left(10 \mathrm{mg} \mathrm{kg}^{-1}\right)$ e cetoprofeno $\left(4 \mathrm{mg} \mathrm{kg}^{-1}\right)$ por via subcutânea 30 minutos antes do procedimento como antibioticoprofilaxia e terapia analgésicoantiinflamatória. Promoveu-se acesso cirúrgico pela face lateral da coxa (bilateralmente) e localizou-se a porção tibial do nervo isquiático, criando-se o defeito por secção completa no terço médio de seu trajeto. Em seguida, uma câmara siliconada $(1,5 \times 2,42 \mathrm{~mm}$; diâmetro interno e externo e $15 \mathrm{~mm}$ de comprimento) foi fixada no epineuro com fio monofilamentar de náilon calibre 6-0. No espaço criado entre os cotos nervosos $(5 \mathrm{~mm})$ do membro esquerdo (grupo tratamento), foi injetada a fração mononuclear autóloga de medula óssea $\left(1 \times 10^{6}\right.$ células em $0,1 \mathrm{~mL}$ ). No membro direito (grupo controle), foi injetado o mesmo volume de $\mathrm{NaCl} 0,9 \%$ internamente à prótese. Utilizou-se lupa cefálica a fim de magnificar a imagem. Os animais foram observados por um período de 30 dias, quando se realizou diariamente exame neurológico, e observação da taxa de deiscência de sutura e da presença de infecção no local do acesso 
cirúrgico. Em seguida, os animais foram eutanasiados para avaliação histológica. As amostras de nervo tibial foram fixadas em dois tipos de soluções: solução de glutaraldeído ou formol tamponado a 10\%.

Processamento, análise das amostras e tratamento estatístico dos dados

Doze segmentos de nervos tibiais (seis animais) foram fixados em glutaraldeído e processados por meio de cortes histológicos semifinos corados com azul de toluidina $0,25 \%$. Essas amostras foram avaliadas qualitativamente. Outras 12 amostras (seis animais) foram fixadas em formol tamponado a $10 \%$, incluídas em parafina, clivadas com três micrômetros de espessura e coradas com luxol fast blue e hematoxilinaeosina (HE). Os cortes histológicos foram avaliados comparativamente de acordo com: presença de células inflamatórias (eosinófilos), formação de câmaras de digestão (degeneração walleriana), visibilização de grânulos de hemossiderina e presença de granulomas ou células gigantes. Desenvolveu-se escore normatizando a pontuação segundo as diferentes variáveis (Tabela 1). Após a tabulação dos dados, realizou-se a análise estatística (SPSS versão 14.0 para Windows) aplicando-se o teste de McNemar para a variável granuloma e o teste de Wilcoxon para as demais. O nível de significância considerado para os testes foi de $5 \%(\mathrm{P}<0,05)$.

\section{RESULTADOS E DISCUSSÃO}

O emprego da técnica de tubulização junto à terapia celular mononuclear autóloga de medula óssea representou bem a tendência de associar técnicas consagradas com métodos inovadores como alternativas para o reparo tecidual.

DA-SILVA et al. (2003) e OLIVEIRA et al. (2004) relatam que numerosos estudos avaliaram a técnica de tubulização demonstrando melhora significativa no processo de regeneração por meio da manipulação do microambiente. Concordando com estes autores e acreditando nas vantagens do processo de tubulização, promoveu-se o estudo dos possíveis efeitos benéficos da utilização de células-tronco autólogas de medula óssea.

$\mathrm{Na}$ avaliação dos resultados, algumas observações não apresentaram diferenças entre os grupos, como exame neurológico (membros posteriores), presença de infecção cirúrgica e deiscência da sutura da prótese. Considerando isso, em conjunto com a subjetividade de avaliação, estas variáveis não foram exploradas com maior profundidade. Também não houve diferença entre os grupos quanto à formação tecidual internamente à câmara, pois em todos os animais observou-se tecido de regeneração formando uma "ponte" interligando as extremidades nervosas. Essas observações vão ao encontro dos achados de DA-SILVA et al. (2003), que também observaram regeneração em todos os animais de seu estudo. CHEN et al. (2007), utilizando $15 \mathrm{~mm}$ de espaçamento entre os cotos nervosos de ratos Wistar e 10 semanas de observação pós-operatória, não encontraram regeneração em todos animais nos diferentes grupos de estudo (grupo células tronco mesenquimais e grupo controle).

Nas lâminas coradas pelo HE, foi constatada a presença de granulomas (Figura 1a) compostos de macrófagos, células epitelióides e células gigantes, além da presença do fio de sutura. No entanto, não foi encontrada diferença significativa entre os grupos de tratamento avaliados a partir desta variável, segundo teste estatístico de McNemar. Estes achados podem ser explicados pelo fato de a reação granulomatosa estar diretamente ligada à presença de material estranho (fio de sutura) no tecido nervoso, indicando reação prolongada entre o hospedeiro e o material estranho (THOMPSON, 1983).

Relacionando as outras alterações histológicas, KARANTH et al. (2006) relatam que a resposta imune facilita a remoção de debris mielínicos e axonais e incita a produção de citocinas e fatores neurotróficos, beneficiando o processo de regeneração axonal. Constituinte desta reação imunológica, a infiltração por eosinófilos foi observada na grande maioria dos cortes histológicos, apresentando valores médios inferiores para o grupo tratamento (Figura 1c).

Tabela 1- Metodologia de avaliação das alterações encontradas nos cortes histológicos corados com HE e luxol fast blue.

\begin{tabular}{llc}
\hline Variáveis & \multicolumn{1}{c}{ Escore } \\
\hline Granuloma & $\begin{array}{c}\text { Presença } \\
\text { Ausência }\end{array}$ & 0 \\
Eosinófilos & Número absoluto; contagem de eosinófilos pelo escaneamento de toda a lâmina histológica. \\
Hemossiderina & Número absoluto; contagem dos focos de hemossiderina pelo escaneamento de toda a lâmina histológica. \\
Degeneração Walleriana & Estimativa (\%) do processo de degeneração walleriana pela contagem de câmaras de digestão por meio do \\
& escaneamento de toda a lâmina histológica. \\
\hline
\end{tabular}

Ciência Rural, v.38, n.9, dez, 2008. 


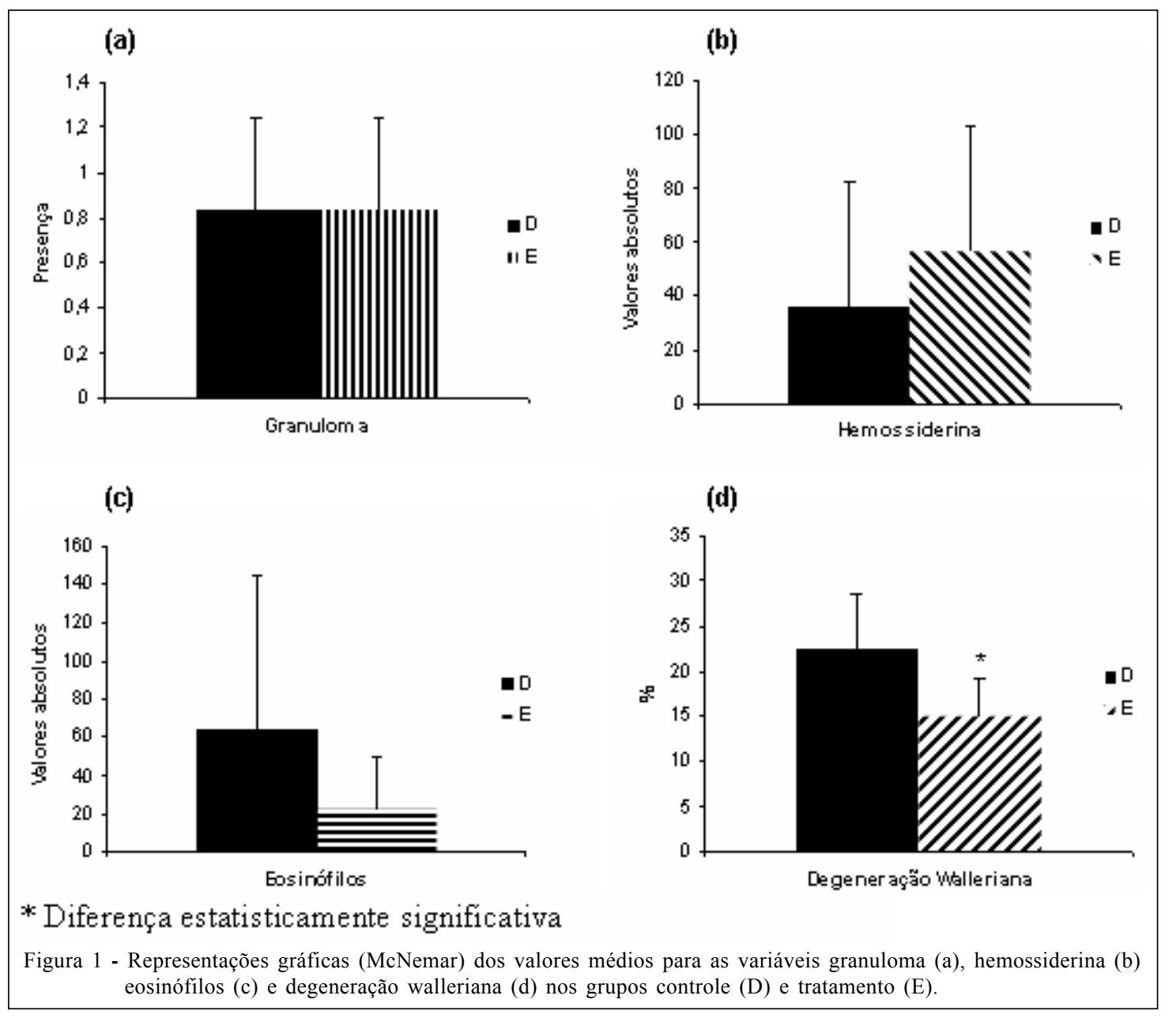

De forma geral, infere-se que a presença em menor quantidade de eosinófilos no grupo tratado esteja ligada à maior velocidade de resolução deste processo e, portanto, sua produção e seu aparecimento estariam em fase de declínio. Contudo, tal diferença não demonstrou significância estatística, segundo teste de Wilcoxon.

Em todas as lâminas foram observados macrófagos carregados de hemossiderina em quantidades discretas. Hemossiderina é um pigmento marrom contendo ferro e usualmente encontrado nos macrófagos do sistema retículo-endotelial. É um achado bastante comum nos tecidos corados por HE, aparecendo na forma de manchas amarronzadas. A quantidade de hemossiderina, dependendo das circunstâncias que deram início ao acúmulo, pode ser uma indicação das reservas de ferro corporal ou de degradação sangüínea. Assim, concentração acentuada de hemossiderina numa área de tecido indica hemorragia prévia (THOMPSON, 1983; GRINDEM et al., 2002). No estudo em questão, constatou-se o aparecimento de focos de hemossiderina em maior taxa no grupo tratado (Figura 1b), contudo, tal diferença não foi estatisticamente significativa segundo teste de Wilcoxon. Outras observações notadas com a avaliação dos cortes histológicos foram expansão do perineuro pela deposição de colágeno ou formação de edema, juntamente com numerosas câmaras de digestão, indicando degeneração walleriana, mais abundantes nas porções distais das secções. Para ALMEIDA (2006), a regeneração após lesão axonal inicia-se com três semanas de evolução e somente ocorre se houver preservação do corpo celular. Para SEIM III (2005), a velocidade de regeneração nervosa em pequenos animais pode atingir até $4 \mathrm{~mm} /$ dia. Em roedores e coelhos, por meio da experiência prática profissional dos autores, pode-se observar, de modogeral, uma velocidade ainda maior de crescimento nervoso, provavelmente em decorrência do metabolismo extremamente acelerado destas espécies. A figura 1d expressa os resultados da análise da variável degeneração Walleriana. A figura 2a demonstra, em 

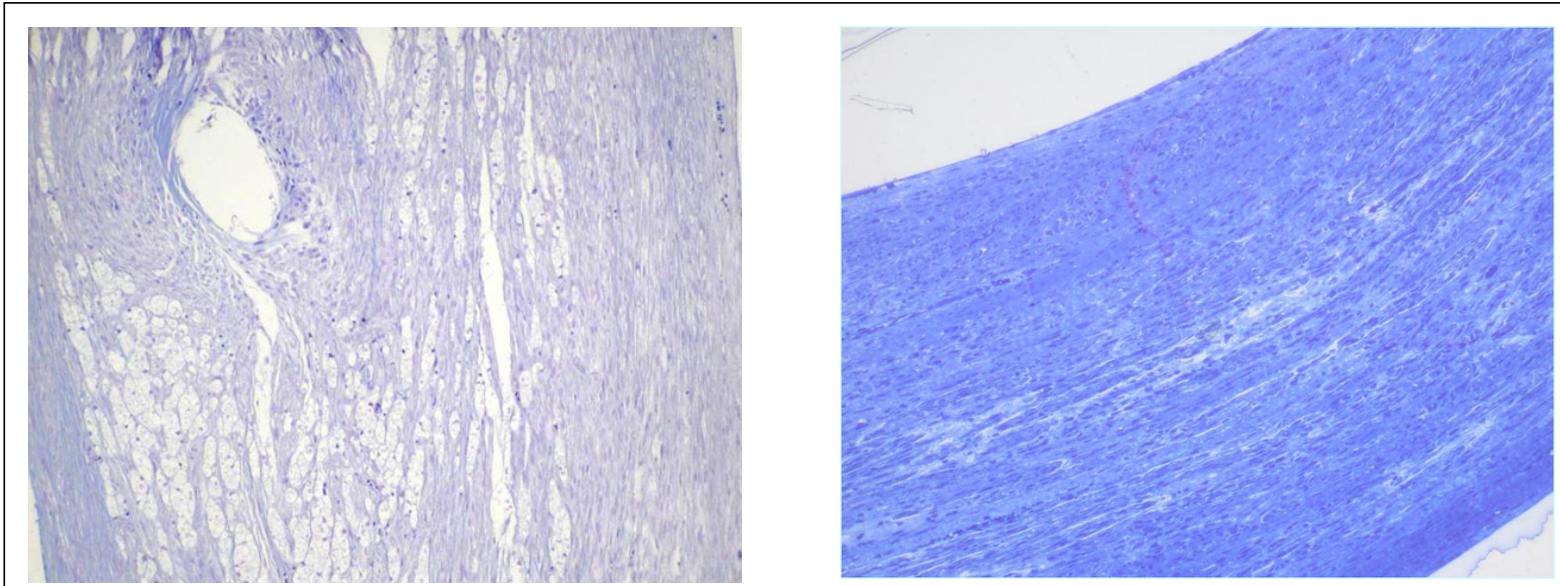

Figura 2 - a)demonstrando: I - degeneração walleriana pela formação das câmaras de digestão e II - defeito deixado pelo material de sutura (luxol fast blue, aumento de 400X); b) padrão de regeneração das fibras nervosas na porção distal do nervo tibial direito de coelhos (azul de toluidina, aumento de 400X). Avaliação com 30 dias de evolução pós-operatória.

corte longitudinal com coloração de luxol fast blue observado em aumento de 400X, a presença de degeneração walleriana pela formação das câmaras de digestão no tecido nervoso regenerado da porção média do nervo tibial e o orifício deixado pelo material de sutura.

Com os cortes histológicos semifinos corados com azul de toluidina, foi avaliada de forma qualitativa a regeneração nervosa. Foram identificadas fibras regeneradas de orientação longitudinal e mielina fina, o que é indicativo de evolução do processo em ambos os grupos de estudo. É fato freqüentemente relatado na literatura que as fibras nervosas regeneradas são envolvidas por internodos de mielina mais finos e mais curtos que as fibras normais (CAVANAGH, 1990). A figura 2b demonstra corte longitudinal semifino corado pelo azul de toluidina $0,25 \%$ e observado sob aumento de $400 \mathrm{X}$, onde podese visualizar o padrão de regeneração das fibras nervosas na porção distal do nervo tibial direito.

Observou-se ainda número variável de neofascículos com fibras desviadas por vasos neoformados de parede fina e luz ampla independente do grupo estudado. CHEN et al. (2007) também observaram em seu estudo maturação e diâmetro axonal incompleto em comparação com nervos saudáveis. Outro achado passível de ser descrito é a identificação de células de Schwann supranumerárias. Por meio da avaliação morfométrica das fibras nervosas regeneradas a ser realizada em uma etapa posterior, será possível mensurar objetivamente variáveis como diâmetro das fibras mielínicas, diâmetro dos axônios mielínicos, espessura das bainhas de mielina e diâmetro dos axônios amielínicos (STOPIGLIA et al., 1998).
Os resultados experimentais deste estudo demonstraram vantagens no processo regenerativo do nervo tibial seccionado, tubulizado e transplantado com células autólogas de medula óssea, embora este estudo não venha elucidar qual é o possível mecanismo de plasticidade ou suporte das células transplantadas ou ainda fatores de crescimento produzidos. Estes achados vão ao encontro do trabalho experimental desenvolvido por CHEN et al. (2007), que demonstraram o benefício do emprego dos aspirados de medula óssea no tecido nervoso lesionado, relatando que célulastronco derivadas de medula óssea, por apresentarem população heterogênea com distinta plasticidade, podem diferenciar-se numa variedade de tipos celulares, incluindo adipócitos, condrócitos, osteócitos, miócitos, hepatócitos, astrócitos e neurônios.

\section{CONCLUSÃO}

A partir dos resultados obtidos é possível concluir que a técnica de tubulização em coelhos proporciona boa evolução do processo de regeneração nervosa em um período de 30 dias de observação póscirúrgica. Pela análise das lâminas histológicas de ambos os grupos, observa-se a regeneração das fibras seccionadas envolvidas com bainhas de mielina finas. Apesar disso, existe diferença significativa entre a presença de degeneração walleriana nos dois grupos de estudo, sendo possível concluir que o tratamento com células-tronco mononucleares autólogas de medula óssea apresenta vantagens no processo de regeneração do nervo periférico sob a técnica de tubulização com 30 dias dias de pós-operatório. No que se refere às demais variáveis analisadas, apesar da 
diferença entre os grupos não ser estatisticamente significativa, é possível inferir que o processo regenerativo acontece de forma mais rápida no grupo tratado com as células-tronco mononucleares autólogas de medula óssea.

\section{COMITÊDEÉTICA}

Este trabalho foi aprovado pelo comitê de ética em pesquisa do Hospital de Clínicas de Porto Alegre (HCPA/ UFRGS), sob o protocolo $06 / 401$.

\section{REFERÊNCIAS}

ALMEIDA, D.F. Trauma de nevo periférico. Capturado em 4 nov. 2006. On line. Disponível na Internet: http:// www.emglab.com.br/html/trauma_de_nervos.html

AQUINO, J.B. et al. In vitro and in vivo differenciation of boundary cap neural crest stem cells into mature Schwann cells. Experimental Neurology, n.198, p.438-449, 2006.

BARTH, W.L. Células tronco e bioética: o progresso biomédico e os desafios éticos. Porto Alegre: Edipucrs, 2006 .

BOYUM A. Separation of leucocytes from blood and bone marrow. Introduction. Scandinavian Journal of Clinical and Laboratory Investigation, Suppl.97, p.7, 1968.

CAVANAGH, J.B. Pathology of peripheral nerve diseases. In: WELLER, R.O. Systemic pathology: nervous system, muscle and eyes. 3.ed. London: Churchill Livingstone, 1990. Cap.20, p.544-577.

CHEN, C.J. et al. Transplantation of bone marrow stromal cells for peripheral nerve repair. Experimental neurology, v.204, p.443-453, 2007.

CHEN, Y.Y. et al. Axon and Schwann cell partnership during nerve regrowth. Journal of Neuropathology and Experimental Neurology, v.64, n.7, p.613-622, 2005.

DAZA, C.H.M. et al. Câmaras de silicona como injerto nervioso, análisis de la especialidad de regeneración del nervio peroneal o tibial: estudio experimental em ratas. Revista Colombiana de Ortopedia y Traumatologia, v.13, n.3, p.285-292, 1999.
DA-SILVA, C.F. et al. Influence of highly purified preparations of hyaluronic acid on peripheral nerve regeneration in vivo. Brazilian Journal of Morphological Sciences, v.20, n.2, p.121-124, 2003.

GRINDEM, C.B. et al. Cytology of bone marrow. Veterinary Clinics of North America: Small Animal Practice, v.32, p.1313-1374, 2002.

HEINE, W. et al. Transplanted neural stem cells promote axonal regeneration through chronically denervated peripheral nerves. Experimental Neurology, n.189, p.231-240, 2004.

KARANTH et al. Nature of signals that initiate the imune response during Wallerian degeneration of peripheral nerves. Experimental Neurology, n.202, p.161-166, 2006.

NARDI, N.B.; ALFONSO, Z.C. Células-tronco hematopoéticas. In: ZAGO, M.A.; COVAS, D.T. Célulastronco, a nova fronteira da medicina. São Paulo: Atheneu, 2006. p.49-65.

OLIVEIRA, A.L.R. et al. Peripheral nerve regeneration through the nerve tubulization technique. Brazilian Journal of Morphological Sciences, v.21, n.4, p.225-231, 2004.

PINEDO, U.G. Utilización de prótesis de quitosana y silicona en la regeneración del nervio ciático axotomizado de ratas. Archivos de Neurociencias Mexicanas, v.6, n.4, p.184193, 2001 .

SEIM III. Cirurgia dos nervos periféricos. In: FOSSUM, T.W. Cirurgia de pequenos animais. São Paulo: Roca, 2005. Cap.43, p.1336-1350.

STOPIGLIA, A.J. et al. Avaliação morfométrica de fibras nervosas do nervo ulnar após reparação cirúrgica com autoenxerto e prótese tubular em cães. Brazilian Journal of Veterinary Research and Animal Science, v.35, n.2, p.8083, 1998

TERENGHI, G. Peripheral nerve regeneration and neurotrophic factors. Journal of Anatomy, v.194, p.1-14, 1999.

THOMPSON, R.G. Inflamação e reparação. In: THOMPSON, R.G. Patologia geral veterinária. Rio de Janeiro: Guanabara Koogan, 1983. Cap.4, p.144-250. 